\title{
Breaking monologues in collaborative research: bridging knowledge systems through a listening-based dialogue of wisdom approach
}

\author{
Adriana Moreno-Cely ${ }^{1}$ [D $\cdot$ Darío Cuajera-Nahui ${ }^{2} \cdot$ Cesar Gabriel Escobar-Vasquez ${ }^{3} \cdot$ Tom Vanwing $^{1}$. \\ Nelson Tapia-Ponce ${ }^{2}$
}

Received: 19 December 2019 / Accepted: 1 March 2021 / Published online: 19 March 2021

(c) The Author(s) 2021

\begin{abstract}
The urgent need to address the sustainability issues of the Anthropocene requires a dialogue capable of bridging different knowledge systems, values, and interests. This dialogue is considered one of the most crucial challenges in collaborative research approaches. With this research, we seek to break with monologues in collaborative research by offering a decolonising methodological approach that combines the notion of dialogue of wisdom, communication theories and ethical principles of Andean philosophy. The methodological framework, the circle of dialogue of wisdom, is the result of an iterative actionreflection process developed in a North-South collaborative research project for territorial planning in Bolivia. Our praxis confirms the potentials offered by a listening-based dialogue for (i) dealing with knowledge-power relations in collaborative research projects, (ii) promoting mutual learning and knowledge co-creation between different knowledge systems, (iii) revaluating local and Indigenous knowledge, and (iv) decolonising the society-science-policy dialogue.
\end{abstract}

Keywords Collaborative research $\cdot$ Indigenous knowledge $\cdot$ Listening $\cdot$ Mutual learning $\cdot$ Knowledge co-creation

\section{Introduction}

Bridging the gap between diverse knowledge systems is becoming a priority and at the same time, a significant challenge in sustainability sciences (Johnson et al. 2016; Chilisa 2017; Hill et al. 2019). During the last decades, there is a greater awareness of the scientific knowledge limitations and the critical role that Indigenous and local knowledge (ILK) plays in dealing with real-world problems (Mistry and

Handled by Julia Leventon, Leuphana University Faculty of Sustainability Scharnhorststr. 1 Lueneburg, Germany.

Adriana Moreno-Cely

adriana.moreno.cely@vub.be

1 Faculty of Psychology and Educational Sciences, Vrije Universiteit Brussel, Brussels, Belgium

2 AGRUCO Research Centre - Faculty of Agricultural, Livestock and Forestry Sciences, University Mayor of San Simon - UMSS, Cochabamba, Bolivia

3 Faculty of Agricultural, Livestock and Forestry Sciences, University Mayor of San Simon - UMSS, Cochabamba, Bolivia
Berardi 2016; Díaz et al. 2018). Although there is an increasing number of scholars interested in finding new pathways to bridge Western and Indigenous sciences, unfortunately, many of these collaborative research practices ended up reproducing dominant (colonial) schemes (Andreotti et al. 2015) and encapsulating fragments of ILK in Western paradigms (Muller 2012). This kind of practices engenders false expectations based on the illusion created by the buzzwords of co-creation, empowerment, and participation (Phillips and Napan 2016). It produces fatigue in communities disappointed by the participatory processes that do not generate real participation or empowerment (Charli-Joseph et al. 2018).

Over the last decades, an increasing number of scholars is advocating for a profound transformation of the nature and purpose of collaborative research (Edwards and Brannelly 2017). This transformation implies "working with, not working on" people (Lieberman 1986), sharing goals and developing each other's ideas, i.e. a collaborative work in which researchers consider local actors as allies instead of participants (Vásquez-Fernández et al. 2018). Essential in this collaborative work is the willingness to share and learn from each other, recognising and valuing each other's 
knowledge and working together to address current societal problems.

In the different forms of collaborative research, interaction with society is critical. Dialogue and participatory approaches are the primary means to co-create knowledge, empowering participants as co-learners or co-researchers, enabling social transformations (Phillips and Napan 2016). However, studies showed that neither dialogue nor participatory methods are a guarantee of equal participation (Herrador-Valencia et al. 2012).

Phillips and colleagues (2018) argue that there is a proliferation of collaborative approaches that take the positive values of dialogue for granted, believing that following dialogical principles and methods are sufficient conditions to achieve democratic and inclusive forms of knowledge production. In line with these ideas, critics of consensus-based dialogue highlight the risks of using dialogical approaches under asymmetric power conditions (Watson 2006; Miraftab 2009).

Academics interested in counteracting the effects of power relations in knowledge production have developed inclusive, decolonising and feminist approaches that try to give voice to those who do not have it (Edwards and Brannelly 2017). These approaches have focused their efforts on developing methodological tools to transform the participants into active agents in a co-creation process (Phillips and Napan 2016). However, some dialogic methodologies tend to romanticise dialogue, ignoring or minimising the impact of power-knowledge tensions on collaborative spaces (Phillips et al. 2018). This position is in strong contradiction with the identified and reported recurring challenges encountered when implementing collaborative work, such as the difficulties of building trust, understanding each other's perspectives, and recognising the value of different knowledge systems (e.g. Chilisa 2017; Hill et al. 2019).

We argue that until now, the efforts made to overcome the challenges of collaborative work have focused on giving a voice to the marginalised and vulnerable populations. Yet, the listening component has been neglected in collaborative research literature. As stated by Gayatri Spivak (1990), reflecting in her seminal work, "Can the subaltern speak?", she points out that the crucial question is "who will listen?" rather than "who should speak?" (Spivak 1990, p. 59).

It is not our intention to dismiss dialogue in collaborative processes. Although dialogue discourse constitutes a form of governance in which knowledge, power and subjectivities end up reducing the possibilities of an inclusive dialogue where all kinds of being and knowledge are recognised and equally valuable (Phillips et al. 2018; Hill et al. 2019). We believe that communication skills, in particular the ability to dialogue, is an integral part of qualitative research methodologies (Fals-Borda and Rahman 1991). We consider it necessary to transform, making the inaudible audible through listening, a stance that requires inner silence, reflexivity, and appreciation of the otherness (Lipari 2010).

This research coincides with Abson and colleagues (2016) work about the possibilities offered by the concept of "deep leverage points" to generate sustainable transformations. A deep leverage point is that place where an intervention aimed at changing mental schemas has great potential to create profound changes in a system. Considering language as "one of the most powerful means by which our conceptual habits are shaped" (Lipari 2010, p. 354), we propose that dialogic listening is a lever with the potential to change the forms of interaction between different types of knowledge. We believe that a mentality shift in how we communicate is necessary to close the gap between diverse knowledge systems. Our contribution seeks (i) to explore alternative pathways in which different types of knowledge co-exist and are enriched by each other; (ii) to delve into the potentialities of listening in an inter-ontological and epistemological dialogue.

We focused our work on the knowledge production realm (Abson et al. 2016) and specifically on the role of academics in bridging different knowledge systems, values, and expectations. This article addresses the need to create a new ethical space in a cooperative spirit (Ermine 2007), i.e. a dialogical space emphasising listening instead of speaking. A listening that takes us beyond the self, not to transform the world but to be transformed (Lipari 2009).

We propose a methodological framework called Circle of Dialogue of Wisdom (CDW) to leverage the possibilities that listening-based dialogue offers to transform collaborative research practices and bridge diverse knowledge systems. This approach takes us beyond dialogue towards a listening engagement with the otherness (Lipari 2009) in which the dyad listening and dialogue are the foundations of social change (Dutta 2014). The framework builds upon three ideas:

(i) The Latino-American Dialogue of Wisdom (DW) considered as a decolonising and sharing space where different cultures, disciplines and knowledge interact and learn from each other (Archila 2017).

(ii) CDW attempts to rethink communication through the lens of listening to the margins (Dutta 2014). A dialogue inspired by Buddhist traditions which focus on listening instead of speaking and judging (Lipari 2010).

(iii) The ethical principles of the Andean philosophy, deeply rooted in the relationality with the other and the otherness (Antequera 2016) guide us in this selfreflective and transformative sharing dialogue.

We developed this methodological framework through a North-South collaborative project in Bolivia as a case study 
that seeks to achieve an inclusive territorial planning and revaluation of ILK to contribute to the self-determination of Indigenous Peoples and Local Communities (IPLC). ${ }^{1} \mathrm{We}$, as indigenous and non-indigenous scholars, embarked with the Bolivian IPLCs, policy-makers and practitioners to navigate uncharted waters with the goal of co-creating new pathways that bridge diverse knowledge systems.

In this paper, we argue that a dialogic listening perspective deserves greater attention, because it creates new directions of communication, that go beyond the discursive thought. We briefly summarise what we mean by a dialogue of wisdom and listening dialogue concepts, highlighting the critical aspects of dialogue and communication in collaborative approaches and giving insights into the ethical principles of Andean philosophy. Finally, by describing our praxis, we shed light on the potentials and challenges of a listening-based dialogue approach.

\section{Dialogue in the spotlight of communication theories}

During the last decades, many scholars, practitioners and decision-makers from different disciplines have been using notions such as co-creation, co-production, co-design, participation, to name the dialogue between diverse stakeholders to produce new knowledge (Phillips 2011). This dialogic turn is becoming a sine qua non condition in research policies and required by funding agencies with an eagerness to create "socially robust knowledge" (Gibbons et al. 1994). However, bridging different types of knowledge, culture, and perspectives is a challenging endeavour, not only because of epistemological and ontological differences but also due to power-related issues. As stated by Watson (2006), using consensus-based knowledge in conditions of power asymmetries will represent an imposition of one group on another, and limit inclusiveness and diversity (Díaz-Reviriego et al. 2019). In the best case, it ends up incorporating some elements of one system into the other, through a validation process imposed by the dominant system (Montana 2017).

Critical analysis of collaborative approaches, conducted by communication researchers, argue that expressions like 'equal footing', 'empowerment', 'participation', and 'dialogue' are buzzwords, turning dialogue and participation into empty discourses (Phillips and Napan 2016). They called for de-romanticising dialogue, arguing that practices which neglect the tensions of power-knowledge arising from

\footnotetext{
${ }^{1}$ Here we will use the international denomination of Indigenous Peoples and Local Communities (IPLC) to name the "Originarios, Indigenas and Campesinos" terms used in the State Constitution to name the 36 ethnies, afrobolivians and peasants in the country.
}

the diversity of interests, values and expectations present in a multi-knowledge-holders exchange could exacerbate exclusion instead of promoting inclusion (Phillips et al. 2018).

Scholars questioning the effects of participation in the neoliberal era argue that hegemonic structures seek to legitimise citizens' perception of inclusion to maintain the hegemonic power using participation and consensus as a tool giving the illusion of an inclusive and equitable decision-making process (Miraftab 2009; Watson 2016). Scholars concerned about these mainstream practices at the science-policy interface proposed to decolonise knowledge production by questioning researchers' deep assumptions (Miraftab 2009) and reflecting on the ethical principles that guide our research practice (Ermine 2007).

\section{Dialogue of wisdom}

The notion of dialogue of wisdom (DW) or dialogo de saberes has its origins in the Participatory Action Research (PAR). It seeks to go beyond the emancipation ideals of empowering the oppressed. DW proposes to create a space for a get-together of different cultures, disciplines and knowledge, recognising each other as equals (Archila 2017), not rhetoric equality, but one that counteracts the cultural, political, economic and mental structures of oppression (Rivera 2012). A space for an inter-ontological and epistemological dialogue, finding possible common ground between different knowledge systems (Rist et al. 2011).

The interest in DW has been growing among Latin-American scholars in the last years pointing to it as a critical factor for the construction of a more equitable, democratic and sustainable world (Rodríguez et al. 2016). Although there are multiple understandings of DW, some refer to it as a collective hermeneutical tool (Ghiso 2000), while others consider it an intercultural dialogue (Rodríguez et al. 2016). Leff (2004) argues that DW is an encounter of collective identities based on cultural autonomies, from where an intercultural dialogue unfolds. DW deactivates the violence of the forced homogenisation of the diverse world, by recognising the other and their knowledge. In other words, DW is not a methodology; it goes beyond a strategy of inclusion and participation. It is a social practice that re-links ethics, ontology, and epistemology, intertwining the real, the symbolic, and the imaginary, in the act of thinking, feeling, and building a diverse world (Leff 2004).

Despite the different understandings of the DW, there are multiple commonalities. First, it is a dialogic sharing space between diverse knowledge systems. Second, it gives the same value to all knowledge systems. Third, it recognises the vital role of ILK in the construction of alternatives to the hegemonic models of knowledge production (Leff 2004; Tapia Ponce 2016; Archila 2017). 
One of the main challenges of DW is how to deal with power asymmetries. Academics argue that it is necessary to work in parallel on the decolonisation of knowledge production, the mind and power structures to reduce power asymmetries (Smith 2012). On the other hand, Ermine (2007) considers that there is a need for another kind of dialogue. One that provides space for "observing, collectively, how hidden values and intentions can control our behaviour, and how unnoticed cultural differences can clash without our realising what is occurring" (Ermine 2007, p. 203). DW is a dialogue in which we embrace the "parallel coexistence of multiple cultural differences that do not extinguish but instead antagonise and complement each other" (Rivera 2012, p. 105).

Similarly, as PAR, DW is attentive to the non-exploitative patterns in social, economic and political life and values such as ideological and spiritual commitment (Fals-Borda and Rahman 1991). Unlike in PAR, in DW the action-reflection is more an internal than external process, which it is developed through listening, appreciation, sensitivity and self-awareness.

\section{A listening dialogue}

Inspired by Eastern philosophical traditions of Buddhism, Lipari (2010) proposes an encounter that goes beyond the limitations of language and binary thinking. In this dialogic space, listening can open new ethical possibilities. This dialogue requires inner silence and awareness of the otherness, where participants engage in a listening-being, embracing difference, uncertainty and plurality. As eloquently expressed by Lipari,

Listening "does not merely tolerate but openly embraces difference, misunderstanding, and uncertainty, and invites entrance to human communication and consciousness beyond discursive thinking, to dwelling places of understanding that language cannot, as yet, reach" (Lipari 2010, p. 360).

To embrace this difference, we need to address the false oppositional dichotomies of "mind versus body; subject versus object; objective truth versus subjective emotion" (Chilisa 2012, p. 271), and try to return to the indigenous relational being, by connecting mind, body, spirit and feelings.

A listening dialogue understands communication as a listening space that puts marginal voices at the centre and critically interrogates the structures of power, goals, agendas and protocols that perpetuate social inequities and render invisible marginal voices (Dutta 2014).

\section{Andean Philosophy}

Ethics and values are vital in collaborative approaches. As academics working with IPLC, we must be aware of our privileges and how our actions may trespass others' spaces and reproduce colonising schemes. Therefore, building ethical spaces in a dialogue between different knowledge systems requires deep reflection on how to define what harms or enhances the wellbeing of the otherness (Ermine 2007).

According to Estermann (2006), there are no equivalent words to values in the Andean philosophy. Like many other indigenous cultures, the Andean world is governed by principles deep-rooted in the relationality with the others and the otherness. Qhari-warmi (Quechua) or Chacha-warmi (Aymara), or double duality, represents a binary relationship between the elements of the world (Antequera 2016). It is the union of opposite pairs that maintain balanced, reciprocal and complimentary relationships (Quiroz 2006, p. 60). This union is possible thanks to the Chakana, which means bridge or the communicative action between opposites that are complementary and corresponding at the same time (Antequera 2016). Two principles govern the relationships between the elements of the Qhari-warmi: the Tinkuy and the Kuti. The Tinkuy is a reunion of opposites, exchange and dialogue with the other. It is what Estermann (2006) calls the principle of relationality, considered as "the life force of everything that exists" (Estermann 2006, p. 111). On the other hand, Kuti is an alternation of opposites, chaos and instability, which can be restored through reciprocity and complementary actions (Estermann 2006).

Three other principles of Andean philosophy are correspondence, complementarity, and reciprocity. The correspondence principle refers to the harmonic correlation between everything that exists in the macro and microcosmos. The principle of complementarity considers that the autonomous and separate individual is incomplete. The individual is only complete and integral when its opposite complements it. Reciprocity is giving back and occurs on multiple levels. A cosmic harmony exists with the reciprocity of actions, manifested in interpersonal relations, with nature and divinities (Estermann 2006). Finally, it is noteworthy that the Andean people of today are the result of multiple colonisations, which have forced them to transform and to reconfigure their way of relating to the outside world. Although these relational principles remain in today's Andean societies, it does not imply that they are non-hierarchical. 


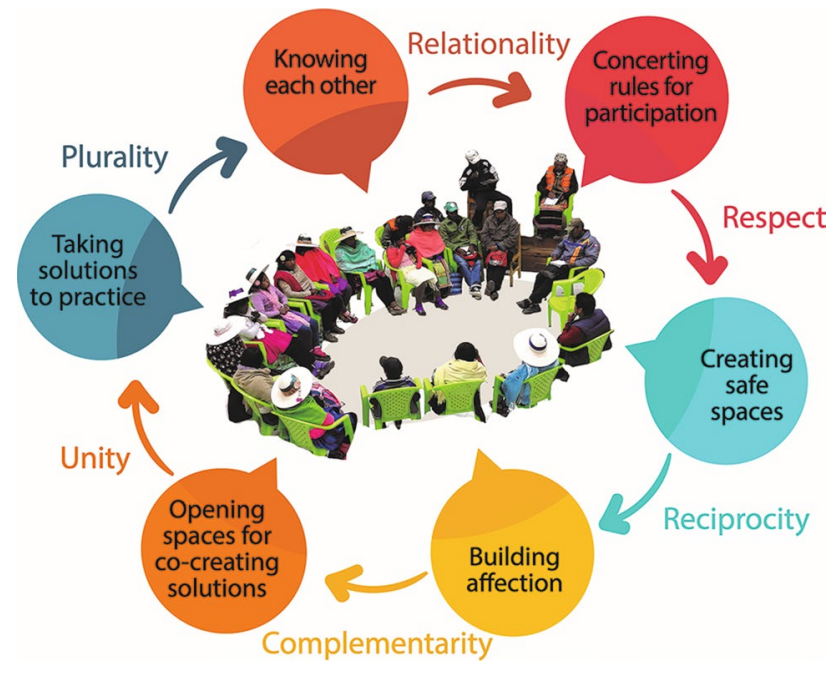

Fig. 1 Circle of dialogue of wisdom, methodological framework

\section{Circle of dialogue of wisdom: methodological framework}

The framework proposed in this paper is a result of a collective reflexivity process. It offers a listening-based dialogue, incorporating the decolonising ideas of DW, supported by Lipari's philosophical notion of listening-being and guided by the ethical principles of Andean philosophy. Considering DW as a decolonising approach, it requires a critical reflexive lens to disrupt damage-centred research practices (Calderon 2016), embracing plurality and diversity. In Fig. 1, we outline the six phases of the Circle of Dialogue of Wisdom (CDW) approach and principles that constituted the route map of our actions-reflections.

In the following paragraphs, we describe the six phases of the CDW; it is noteworthy that the steps should not be considered a linear process, but rather iterative and spiral. We also acknowledge that each collaborative experience is unique. However, we believe that our suggested framework can offer a quantum leap not only related to partners relationships but also as proposed by DW to reconceptualise participation, empowerment and collaboration.

\section{Knowing each other}

At the beginning of every relationship, we need to know who is with us and the best way to discover it, according to Shoter (2009) is through listening in a way that we can recognise and connect to the world of the other. This connection implies building ethical relations (Shotter 2009) framed around four (Rs) principles: relational accountability, respectful representation, reciprocal appropriation and rights and regulations (Louis 2007). To guide this listening phase, we propose some questions to ponder about our real motivations in building the partnership but also reflecting if the community benefits from research. This phase is crucial to building a partnership and creating "the sense of a collective-we" (Shotter 2009, p. 40) and the best way to do it, is by being honest and sympathetic.

\section{Concerting rules}

This phase consists of setting out the rules of participation and the needs of participants. It requires reflecting on the processes and how we can go from symbolic participation towards the creation of a respectful and supportive alliance, where all parties have responsibilities and obligations to maintain the collective-we (Shotter 2009). One strategy is following the three-layer method that includes the self, inter, and collective reflexivity (Nicholls 2009). As stated by Dutta (2014), reflexivity as a critical tenet of listening must be vigilant of the intention that resides in the researchers and their interactions. CDW should not be understood as another encounter where people meet to talk. CDW is an ethical space to engage in a dialogue of wisdom, with a real interest in listening to the other(s), discovering new things, embracing diversity, complementarity and divergence (Leff 2004).

\section{Creating safe spaces}

CDW considers each sharing moment as an ethical space, where we can express to each other deepest thoughts without fear in safe spaces where participants can build trustful and respectful relationships (Charli-Joseph et al. 2018). Safety is also related to fear, the unknown, situations where we do not know the other(s), the language, and the topic we discuss. These situations create discomfort and anxiety, which makes it challenging to connect with the other. Safety is related to harmony, regardless of whether or not different parties agree. Even in moments of misunderstanding, in the end, the balance should return if we comply with CDW principles.

The use of participatory tools can help to build this connection by transforming participants into allies, paying attention to power-relations, plurality and diversity, through (i) Hands-on workshops, participatory mapping and participatory scenario planning using them as boundary elements to engage participants in reflexivity moments of sharing (Steelman et al. 2015); (ii) Honour cultural protocols (Kovach 2010), with rituals, or ceremonies depending on participants' beliefs; (iii) Promote solidarity and empathy (CharliJoseph et al. 2018), using alternative spaces such as having a drink or sharing a moment outside of the work environment to create close relationships which reinforce positive 
exchanges in more formal moments. In spaces where power relations are challenging to overcome, anonymity can be a strategy to break the silence and hear the voices of the less powerful participants. The goal of these strategies is to make people comfortable with and within the group, so they can freely express their opinions and beliefs, breaking with the privilege of the powerful.

\section{Building affection}

Building affection is recognising the value and potential that exists in diversity. This recognition is the basis of the reciprocity and complementarity principles of Andean philosophy. If we receive something from the other, we feel the need to reciprocate and give the other something back. These practices strengthen the relationships in the community (Antequera 2016). Similarly, in a collaborative project, helping each other, sharing different tasks regardless of position, complementing each other (senior or junior researcher, practitioner or local leader), strengthens group ties and creates more horizontal relationships.

This stage of CDW is putting people at the centre, valuing their qualities and knowledge. It is related to sentiments and fondness; it is about learning to be a sentipensante, an "empathy-oriented researcher, who not only conducts research for academic purposes but also creates critical and ethical research that is based on solidarity" (Datta 2018, p. 16).

\section{Co-creating solutions}

How many of the collaborative projects in which we have participated have unintentionally ended up being monologues disguised as dialogue? This type of monologue "seeks to command, coerce, manipulate, conquer, dazzle, deceive or exploit" (Johannesen 1971, p. 377), to achieve the consensus of the audience and impose its truth.

Only by acknowledging our unquestioned assumptions and analysing how different interests and values interfere in our dialogues, we can stop our monologues and start listening to others and learning from each other (Lipari 2010). We do not suggest that CDW are spaces free of power relations and asymmetries but being aware of them allows us to address them (Reid et al. 2016).

By creating learning communities, we can open collaborative solutions spaces where partners share their knowhow, expertise, time and all their available resources for the well-being and benefit of the group. In such an environment, participants think together, freely sharing knowledge, and welcome all ideas. However, this is not an easy task, because it implies changing old ways of thinking (Ermine 2007), and decolonising not only our minds but also our actions (Smith 2012). This collaboration can be possible by exploring multiple solutions, giving privilege to marginalised voices, re-valuating ILK, resisting dominant discourses and decolonising researcher-driven leadership through listeningbeing (Lipari 2010).

\section{Taking solutions to practice}

In collaborative projects, it is necessary to take the time to analyse the effects and benefits of the proposed activities, adopting a listening-being attitude to be connected to the others and, at the same time, being aware of the inevitable power differences (Lipari 2010). It implies sharing actions and responsibilities. It entails co-designing the solutions and co-monitoring and co-evaluation, embracing the plurality of rationalities where different knowledge systems have a place (Chilisa 2017), and building collective ownership (Datta 2018). We could say that the ultimate goal should be to construct a polyphony of voices, as in a choir with different types of voices: soprano, contralto, tenor, and bass co-exist in harmony, but each voice keeps its own identity.

In summary, the CDW approach centres on ethical principles that guide our thoughts and actions. It is a ritual where we share knowledge, beliefs and feelings in safe spaces created by respect, empathy and affection. The goal of this iterative self-inter-collective reflective process is to learn to listen to each other, to learn "to see our own privilege, our own context, our own deep colonising" (Johnson et al. 2016, p. 3), to discover new rationalities by embracing difference, complementarity and plurality and learning to transform ourselves by sharing knowledge, dreams and responsibilities. The six phases and the guiding principles are summarised in Table 1, offering a non-extensive list of methods and questions to ponder.

\section{Circle of dialogue of wisdom: the praxis}

Although the proposed methodological framework seems easy to implement at first glance, in practice, it is a process that requires a profound change in the way of thinking, acting, and communicating. It implies a genuine commitment to decolonise our thoughts. It requires permanent surveillance of our subjectivities and how they reproduce colonial schemes. It also needs significant efforts to learn to listen to the intangible within each one of us. The CDW praxis allowed us to recognise how difficult it can be to change our habits of mind. Also, we witnessed the potential of listeningbeing to reflect on our unquestioned assumptions, values and hidden interests. CDW helped us to develop creative ways to deal with power-relations and, at the same time, re-valuating 
Table 1 Circle of dialogue of wisdom—methodological framework phases

\begin{tabular}{|c|c|c|c|c|}
\hline Phases & Guiding principles & Goals & Activities and methods & Questions to ponder \\
\hline Knowing each other & Relationality & $\begin{array}{l}\text { Cultivating relational } \\
\text { accountability } \\
\text { Build an ethical relationships } \\
\text { Creating a collective-we }\end{array}$ & $\begin{array}{l}\text { Multi-lateral meetings } \\
\text { Face-to-face encounters } \\
\text { Assemblies } \\
\text { Listening-being (Lipari 2010; } \\
\text { Chilisa 2012; Smith 2012) }\end{array}$ & $\begin{array}{l}\text { Do we know the socio-political } \\
\text { environment of the project? } \\
\text { Does the research benefit the } \\
\text { community? } \\
\text { Who must be involved in the } \\
\text { search for solutions? } \\
\text { What are our real motivations } \\
\text { in this partnership? } \\
\text { How differences in culture, } \\
\text { worldviews, etc. affect our } \\
\text { dialogue? }\end{array}$ \\
\hline Concerting rules & Respect & $\begin{array}{l}\text { Being sentipensante } \\
\text { Reconstruct ethical principles } \\
\text { and values } \\
\text { Learn to listen }\end{array}$ & $\begin{array}{l}\text { Multi-layered reflexivity } \\
\text { (Self, interpersonal and } \\
\text { collective) and positionality } \\
\text { (Nicholls 2009) }\end{array}$ & $\begin{array}{l}\text { What is our positionality? } \\
\text { What is our role in the } \\
\text { research? } \\
\text { What are the conditions needed } \\
\text { to engage with the partici- } \\
\text { pants in a listening dialogue? } \\
\text { What are our hidden assump- } \\
\text { tions, values and interests? }\end{array}$ \\
\hline Creating safe spaces & Reciprocity & $\begin{array}{l}\text { Unlearn our privileges } \\
\text { Learn to trust } \\
\text { Develop empathy skills } \\
\text { Build ethical spaces }\end{array}$ & $\begin{array}{l}\text { Using anonymity to deal with } \\
\text { power } \\
\text { Workshops, participatory } \\
\text { mapping, scenario plan- } \\
\text { ning, } \\
\text { Rituals ceremonies (Chilisa } \\
\text { 2012; Smith 2012; Steel- } \\
\text { man et al. 2015) }\end{array}$ & $\begin{array}{l}\text { Are we using our privilege to } \\
\text { impose our views? } \\
\text { Do our methods contribute to } \\
\text { marginalising participants? } \\
\text { What should be done to trans- } \\
\text { form fear in trust? } \\
\text { Are we comfortable with the } \\
\text { partners? Do they feel com- } \\
\text { fortable with us? }\end{array}$ \\
\hline Building affection & Complementarity & $\begin{array}{l}\text { Learn to share } \\
\text { Strengthen relationships } \\
\text { Create synergies } \\
\text { Putting people at the centre }\end{array}$ & $\begin{array}{l}\text { Valuing people's qualities } \\
\text { Sharing tasks and respon- } \\
\text { sibilities (Chilisa 2012; } \\
\text { Smith 2012) }\end{array}$ & $\begin{array}{l}\text { Are we giving more than } \\
\text { receiving, or do we expect to } \\
\text { receive more than we offer? } \\
\text { Are we giving spaces for emo- } \\
\text { tions and feelings? Or are } \\
\text { we only paying attention to } \\
\text { knowledge? }\end{array}$ \\
\hline Co-creating solutions & Unity & $\begin{array}{l}\text { Embrace complexity and } \\
\text { uncertainty } \\
\text { Re-valuate ILK } \\
\text { Decolonising knowledge, } \\
\text { being and actions }\end{array}$ & $\begin{array}{l}\text { Building learning communi- } \\
\text { ties } \\
\text { Land-based learning } \\
\text { approaches } \\
\text { Sharing information, spiritu- } \\
\text { ality and emotions (Chilisa } \\
\text { 2012; Smith 2012) }\end{array}$ & $\begin{array}{l}\text { Are we aware of dominant } \\
\text { discourses? } \\
\text { Are we open to ontological and } \\
\text { epistemological differences } \\
\text { and pluralism? } \\
\text { Do we value local knowledge } \\
\text { as scientific? } \\
\text { Do research activities, and } \\
\text { practices perpetuate colonial } \\
\text { schemes and values of the } \\
\text { elite? } \\
\text { Are we listening and valuing } \\
\text { all proposals? }\end{array}$ \\
\hline Taking solutions to practice & Plurality & $\begin{array}{l}\text { Unlearning to compete } \\
\text { Learn to work together } \\
\text { Build collective responsibil- } \\
\text { ity }\end{array}$ & $\begin{array}{l}\text { Sharing responsibilities } \\
\text { Co-design } \\
\text { Co-monitoring } \\
\text { Co-evaluation (Chilisa 2012; } \\
\text { Smith 2012) }\end{array}$ & $\begin{array}{l}\text { Are we sharing control? } \\
\text { Are we (and how) reducing } \\
\text { the effects of power in the } \\
\text { decision-making processes? } \\
\text { What actions do we take to } \\
\text { guarantee real partnership in } \\
\text { all stages of the process? }\end{array}$ \\
\hline
\end{tabular}

ILK. In the following lines, we summarise some of the challenges and lessons learned derived from our praxis working with our Bolivian partners.

\section{Applying the CDW in the context of Bolivia}

In 2016, Bolivia promulgated a new territorial planning law (Ley 777 del Sistema de Planificación Integral 
Estatal-SPIE) within the framework of Vivir Bien (living well) adopted by Bolivia as an alternative paradigm that arises from a profound criticism of the so-called development in the West (AGRUCO 2011). SPIE Law reflects Bolivia's strategy to face the challenges of climate change presented at the United Nations Framework Convention on Climate Change (UNFCCC) and in the Intergovernmental Platform on Biodiversity and Ecosystem Services (IPBES) (Pacheco 2016). The SPIE is the result of a long society-science-policy dialogue that started at the National Constituent Assembly in 2006, where many academics participated in the discussions with the different IPLC representatives to coordinate planning activities with climate change and risk management strategies (AGRUCO 2011; Pacheco 2016; FAO 2018).

Part of the SPIE system is a 5-year management plan at the municipality level, named Planes Territoriales de Desarrollo Integral (PTDI) (Territorial plans for comprehensive development). The PTDI adopts the notion of Living Systems (LS) for integrated management of territories. Understanding LS as harmonic systems of the Mother Earth with the two components: Nature (Zonas de Vida) and People (Unidades Socio-Culturales) (Estado Plurinacional de Bolivia 2016). PTDIs are meant to (i) improve operational planning, (ii) enhance the potentiality of living systems, and (iii) increase well-being by integrating social, cultural, political, economical and ecological dimensions of living well (Estado Plurinacional de Bolivia 2016).

\section{Sharing knowledge and control: building the alliance}

At the end of March 2017, a partnership was created between Bolivian and Belgian universities. Together with the communities and policy-makers, we developed a suitable methodological tool based on ILK and constructed it with IPLC. During six months, we discussed ideas for a project. The main interlocutors from Bolivia were two agronomists with extensive experience in agroecology and ILK. From the Belgian side, there was a Belgian professor and a Colombian researcher from educational sciences with more than 15 years experience of working with IPLC in Suriname and Colombia, respectively. The communication between us was fluid, not only because our research interests matched but also because of our values and commitments. Although the incentives for our relationships were primarily personal interests at first, our shared values quickly strengthened our ties. Our joined efforts paid off with a 2-year collaborative project. The project objective was to promote a society-science-policy dialogue to enhance the methodological guidelines of PTDI by building differentiated qualitative indicators that could measure the different dimensions of Vivir Bien-using as case studies three Bolivian municipalities (Bolivar, Totora and Vacas).

Before starting the project activities, we set-up the research agenda, and signed memoranda of understanding with the local community partners. Each municipality appointed a local co-leader and interlocutors for the project, and communities selected the co-researchers who participated in the different activities of the project. In the academic team were two professors, one from each university, three $\mathrm{PhD}$ researchers, two from Bolivia and one from Belgium, three master students and three undergraduate students, all from Bolivia. The academic team consisted of male and female researchers from different disciplines (social and natural sciences), and five of them were Quechua native speakers.

Communities requested to be informed about the SPIE Law and wanted training in agroecology practices. To comply with this reciprocity act, we coordinated with the municipalities and their local institutions and set up a training course. This space gave us the possibility to enter the communities and start building closer relationships, discovering the environment and sharing daily life with IPLC before beginning the project's activities. Table 2 presents an overview of the actors involved in the activities of the project.

\section{Our assumptions}

When the project started, we considered that the conditions were optimal for collaborative work. The project idea came from a real problem expressed by the municipalities. Academic partners elaborated the proposal together and agreed on the scope, and project goals, complying with the requirements of the municipalities and the IPLC. At first glance, we thought it was going to be an easy collaborative project to carry out, but reality showed us that the conditions were far from ideal.

Our assumptions, interests and perspectives were present since we started writing the project proposal, we began by assuming that:

- Local authorities and IPLC were highly interested in the possibilities that the law offered to integrate the Vivir Bien approach into their territorial planning.

- The difficulties in implementing the new legal framework were mainly due to technical and economic reasons.

- A Bolivian legal framework, promoted by an indigenous government, offered more possibilities to participate for IPLC (including women). 
Table. 2 Participants and topics developed in the CDWs per municipality

\begin{tabular}{|c|c|c|c|}
\hline Municipality & Territories & Actors & Topics \\
\hline Totora & $\begin{array}{l}\text { South District: (Tika } \\
\text { pampa, Laguna) } \\
\text { North District: } \\
\text { Antaqhawa } \\
\text { 1 District } \\
\text { East District } \\
\text { Machu Yungas } \\
\text { Yungas de Vandiola }\end{array}$ & $\begin{array}{l}\text { Agrecol Andes foundation, } \\
\text { Totora parish } \\
\text { Emapaq association } \\
\text { Molla Pampa association } \\
\text { Bartolinas association } \\
\text { APRAE association } \\
\text { Association of irrigators } \\
\text { Association of vegetable producers } \\
\text { Association of irrigator } \\
\text { Union peasant Leaders } \\
\text { Municipal authorities }\end{array}$ & $\begin{array}{l}\text { Agricultural production } \\
\text { Food security } \\
\text { Water availability, quality and management } \\
\text { Migration } \\
\text { Education } \\
\text { Health } \\
\text { Sacred places } \\
\text { practices } \\
\text { The relevance of local biodiversity } \\
\text { Agroecological practices }\end{array}$ \\
\hline Bolivar & $\begin{array}{l}\text { Highlands } \\
\text { Lowlands } \\
\text { Valleys }\end{array}$ & $\begin{array}{l}\text { Indigenous organisation (Ayllus) } \\
\text { Bartolinas association } \\
\text { Union peasant Leaders } \\
\text { Municipal authorities }\end{array}$ & $\begin{array}{l}\text { Agriculture } \\
\text { Food security } \\
\text { Water management } \\
\text { Migration } \\
\text { Education } \\
\text { Health } \\
\text { Conflict Indigenous organisation and peasants' unions }\end{array}$ \\
\hline Vacas & $\begin{array}{l}\text { Rodeo District } \\
\text { Totora Pampa } \\
\text { Rodeo community } \\
\text { Juntutuyo } \\
\text { Canadas District } \\
\text { Paredones District }\end{array}$ & $\begin{array}{l}\text { Bartolinas association } \\
\text { Association of fish farmers } \\
\text { Union peasant Leaders } \\
\text { Municipal authorities }\end{array}$ & $\begin{array}{l}\text { Organisational conflicts } \\
\text { Water availability and management } \\
\text { Project funding }\end{array}$ \\
\hline
\end{tabular}

- We could improve women's participation through working with female researchers and speaking the local language.

In the beginning, municipal authorities acknowledged that their main problems were the lack of qualified personnel and resources to carry out inclusive planning as proposed in the law. When we started our CDW with IPLC, we understood that although the above problems were accurate to some extent, other underlying reasons and local realities were slipping out of sight.

We started listening to not only multiple and contradictory voices but also silences that gave us a different perspective on the problem. These voices and silences showed us that (i) it was not only a methodological issue that could be solved with researchers speaking the same language.

(ii) Even if proposed by an indigenous government, a legal framework does not automatically guarantee the inclusion and self-determination of IPLC.

Especially during the knowing each other phase, but also throughout creating safe spaces and building affection phases, we identify and reflect on power issues, political struggles, unresolved conflicts, corruption, migration, modernity, and gender inequality, among other realities. All these were present in the territories and affected the engagement and self-determination of IPLC. We understood that talking about territorial planning without considering these realities would be a form of blindness.
In a collaborative process, it is essential to take the time to discover the context, and listening offers an opening for interrogating the inequities of power distribution (Dutta 2014). We must not forget that collaboration takes place in a specific and unique environment that we need to explore with an open mind and without judgements, paying attention to avoid perpetuating the values embedded in the interest of the elite and their power structures.

\section{Dealing with power-knowledge relations}

Bolivia is a hierarchical society where multiple factors, such as titles, origins, and even gender, determine relationships. These power scales were evident in all spaces, within the academic team, in the communities and also in gender relationships. Considering the academic project team, we perceived that power-knowledge and gender relations were affecting the possibilities of dialogue between equals during the CWD meetings.

Although horizontality was emphasised and everyone was encouraged to participate, introvert students-mainly women-were always silent. After several attempts using participatory tools, we recognised that they did not feel safe enough to express themselves in those spaces. Creating safe spaces and co-creating solution phases helped us to overcome this issue, we incorporated an anonymity strategy to create a safe space for interaction. We used the traditional 
Fig. 2 Example of a practical workshop, beekeeping in Totora Municipality photograph by Adriana Moreno

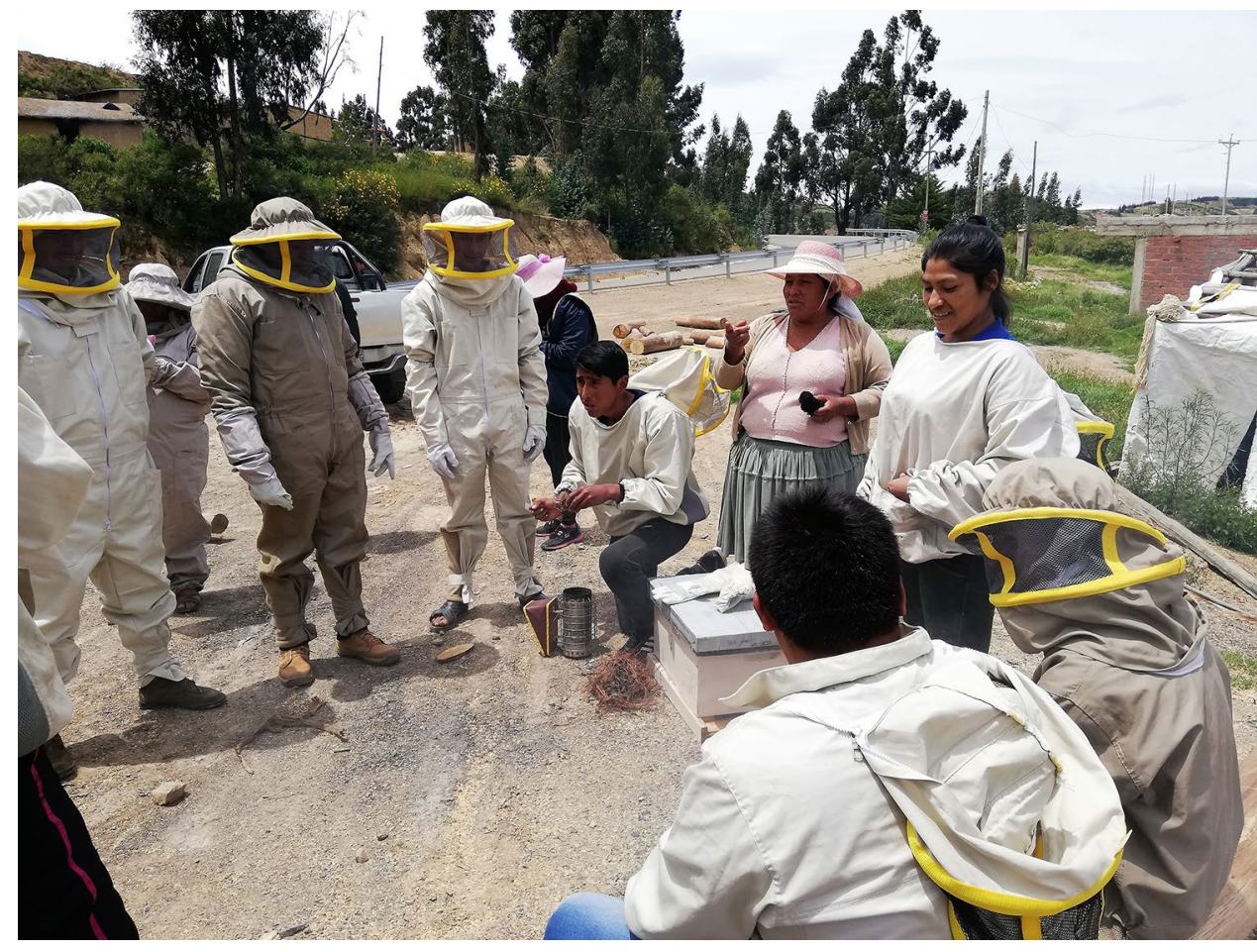

pen and paper option to write down answers to discussion topics. The anonymously written topics were stuck on a pinboard to open public discussion. When anonymously raised topics/issues became available, it was easy to talk about them, construct solutions together, and share responsibilities when implementing the solutions, promoting complementarity and unity. The approach did not only guarantee that all voices were heard, but also that power was redistributed, considering each participant's interests and expertise, embracing plurality.

CDW helped the academic team to look at power-knowledge in teacher-student and peer-to-peer interactions and propose alternative ways to support an active-project-based learning methodology. Especially, the last three phases of our methodological framework gave us ideas about how to provide students with the responsibility and opportunity to take part during their learning process by acquiring and applying new knowledge in a real problem-solving context. Making the imperceptible voices audible helped alter power relationships, prejudice and the complex dynamics within the project team. It allowed silent students to be heard and provided spaces to reflect, breaking dominant discourses through listening. Our CDW approach provided elements to deal with these problems while improving mutual and cross-cultural learning and knowledge co-creation through our relational accountabilities (Datta 2018).

\section{Re-valuating Indigenous and local knowledge}

Concerning power-knowledge issues within the communities, the strategy was to create spaces for mutual learning while re-valuating ILK. The training sessions, which were reciprocity acts, became crucial spaces for sharing and empowerment with the IPLC, Non-Governmental Organisations (NGOs) and local authorities. Together, we succeeded to build a team by embracing Andean philosophy and sharing knowledge and control. The training consisted of three moments: the first moment where a proposed problem was discussed from the local perspective while trying to find the key challenges. In a second moment, participants were asked to reflect on how they solve the problem in their communities and investigate how older people, wise men/women handled the situation. The participants had to prepare re-valuation cards, explaining the problem and solutions based on local knowledge. Later, participants shared their work with the group. In a third moment, we implemented a practical workshop combining ILK with academic and practitioner knowledge, which resulted in the co-creation of new practical knowledge that can easily be applied in their communities, illustrated in Fig. 2. Another important outcome of the training sessions was that co-leaders were empowered, and their leadership was crucial in working with the communities. Co-leaders were in charge of guiding the CDW together with the academic team; their leadership helped to create 
safe and inclusive spaces where participants felt more comfortable to share their knowledge and experiences.

As mentioned before, it is crucial to take the time to discover the context that surrounded us and adapt different participatory tools accordingly. In our case, workshops, participatory mapping and participatory scenario planning were other co-creation moments that allowed us to articulate different visions of the past, present and future, which contribute at the same time, to reconstruct historical memory and to revitalise ILK (Rodríguez and Inturias 2018). Our praxis also showed us the relevance of the reflexivity between peers to address participants' interests and concerns and, at the same time, unfold ILK.

\section{Decolonising knowledge, actions and beings}

Another challenge we encountered in the three municipalities was to promote women as active participants. At the beginning, most women who came to the meetings remained silent and did not feel comfortable speaking in public. Although the principle of complementarity between men and women (Qhari-warmi) is widely defended by Andean people, in reality, few women participate in decision-making spaces. Most of the time, women have been co-opted by men in organisations and political parties (Rousseau and Hudon 2017). Entering political spheres which have been exclusive to men represents a high risk to be subjected to sexual harassment and lose legitimacy for the public representation of women (Rivera 2015). When talking to a woman leader in Totora, she explained that women do not participate, because they are timid to speak in public. She was also afraid but participating in training and meetings like the ones we organised, helped her learn to be a leader and urge other women to do the same.

Despite the efforts to close the gender gap in Bolivia by incorporating relevant legislation and including women in decision-making spaces, gender inequality persists. Changes at the institutional level do not have enough leverage to generate transformations. It is necessary to develop programmes and strategies in the planning process, specially designed for women, by women, to enhance women's participation in planning and decision-making spheres. To promote gender equality, as stated by Rivera, there is a need for a simultaneous effort of cultural and gender decolonisation (Rivera 1997). We observed that although legal and institutional frameworks could be a leverage point to generate sustainable transformations as proposed by Abson et al. (2016), we considered that for these legal frameworks not to remain rhetorical, it is necessary to empower citizens to take ownership. This empowerment can begin by revitalising ILK and turning communities into allies.

\section{Conclusions}

The CDW approach proposed in this paper offered guidance in using the potential of new dialogic forms based on listening for the construction of parallel coexistence of multiple knowledge systems. Building on reciprocity, complementarity and respectful relationships, this approach opened up new possibilities for knowledge co-creation in collaborative research. The suggested CDW framework was a dialogue of wisdom in itself, in which concepts from Western science, Buddhist and Andean philosophy were put into dialogue, valuing what each one can offer, demonstrating that it is possible to build bridges between knowledge that seemed dissonant.

We demonstrated how CDW leveraged listening-based dialogue to transform collaborative research practices and bridge diverse knowledge systems. In the same way, we emphasised how CDW strengthened mutual and cross-cultural learning, revitalising ILK and decolonising teaching and research practices. CDW helped in the reconstruction of collective memory to understand local realities better and discover hidden dynamics in the communities. With the CDW, we were able to visualise new paths of collaborative research practices, addressing power imbalances and colonised and dominant discourses, striving to establish reciprocity and coexistence pacts between different knowledge systems. The benefits that this kind of listening dialogue could bring are multiple, not only for planning endeavours but also for society-science-policy encounters in other domains where power relations affect collaboration and in co-creation spaces that involve different knowledge systems.

Acknowledgements We are grateful to the two anonymous reviewers for their generous time, a careful reading of our manuscript, thoughtful, constructive criticism, and insightful comments. Their provocative questions and suggestions led to radical rethinks of the manuscript's arguments and organisation that significantly improved the final version. We would also like to show our gratitude to Kim Hardie for the English proofreading and Josue Aranibar for the illustrations. We want to thank our colleagues and allies' invaluable collaboration in the municipalities of Totora, Bolivar and Vacas, and the communities' generosity for sharing their knowledge, dreams, and hopes. This study has been partially supported by the Belgian Development cooperation trough Flemish Interuniversity Council-University Cooperation for development (VLIR) within the South Initiative project "Co-creating new knowledge through joint learning on life systems for adapting territorial development plans-Wakichina".

Open Access This article is licensed under a Creative Commons Attribution 4.0 International License, which permits use, sharing, adaptation, distribution and reproduction in any medium or format, as long as you give appropriate credit to the original author(s) and the source, provide a link to the Creative Commons licence, and indicate if changes were made. The images or other third party material in this article are included in the article's Creative Commons licence, unless indicated otherwise in a credit line to the material. If material is not included in the article's Creative Commons licence and your intended use is not permitted by statutory regulation or exceeds the permitted use, you will need to obtain permission directly from the copyright holder. To view a copy of this licence, visit http://creativecommons.org/licenses/by/4.0/. 


\section{References}

Abson DJ et al (2016) Leverage points for sustainability transformation. Ambio 46(1):30-39. https://doi.org/10.1007/s13280-016-0800-y

AGRUCO (2011) Agroecologia y desarrollo endogeno sustentable para vivir bien: 25 años de la experiencias de Agruco. Cochabamba. http://biblioteca.clacso.edu.ar/Bolivia/agruco/20170928052016/ pdf_223.pdf

Andreotti V et al (2015) Mapping interpretations of decolonization in the context of higher education. Decolonization Indigeneity Educ Soc 4(1):21-40

Antequera N (2016) Debemos gobernarnos a nosotros mismos. Organizacion politica originaria del ayllu andino (Kirkyawi-Bolivia). Tiquipaya: Tupac Katari

Archila M (2017) Cómo entender el diálogo de saberes. LASAFORUM 48(2):61-62

Calderon D (2016) Moving from damage-centered research through unsettling reflexivity. Anthropol Educ Q 47(1):5-24. https://doi. org/10.1111/aeq.12132

Charli-Joseph L et al (2018) Promoting agency for social-ecological transformation: a transformation-lab in the Xochimilco social-ecological system. Ecol Soc. https://doi.org/10.5751/ ES-10214-230246

Chilisa B (2012) Indigenous research methodologies. SAGE Publications

Chilisa B (2017) Decolonising transdisciplinary research approaches: an African perspective for enhancing knowledge integration in sustainability science. Sustain Sci 12(5):813-827. https://doi.org/ 10.1007/s11625-017-0461-1 (Springer Japan)

Datta R (2018) Decolonizing both researcher and research and its effectiveness in Indigenous research. Res Ethics 14(2):1-24. https:// doi.org/10.1177/1747016117733296

Díaz S et al (2018) Assessing nature's contributions to people. Science 359(6373):270-272. https://doi.org/10.1126/science.aap8826

Díaz-Reviriego I, Turnhout E, Beck S (2019) Participation and inclusiveness in the intergovernmental science-policy platform on biodiversity and ecosystem services. Nat Sustain 2(6):457-464. https://doi.org/10.1038/s41893-019-0290-6 (Springer, US)

Dutta MJ (2014) A culture-centered approach to listening: voices of social change. Int J Listening 28(2):67-81. https://doi.org/10. 1080/10904018.2014.876266

Edwards R, Brannelly T (2017) Approaches to democratising qualitative research methods. Qualitative Res 17(3):271-277. https://doi. org/10.1177/1468794117706869

Ermine W (2007) The ethical space of engagement. Indigenous Law J 6(1):193-203

Estermann J (2006) Filosofia Andina. Sabiduria indigena para un mundo nuevo. Segunda. In: ISEAT (ed). ISEAT, La Paz

Fals-Borda O, Rahman M (1991) Action and knowledge: breaking the monopoly with participatory action-research. In: Fals-Borda O, Rahman M (eds). The Apex Press, New York

FAO (2018) Plataforma de territorios inteligentes, experiencias territoriales. http://www.fao.org/in-action/territorios-inteligentes/artic ulos/experiencias-territoriales/detalle/es/c/1149343/. Accessed 4 May 2020

Ghiso A (2000) Potenciando la diversidad: Dialogo de saberes, una practica hermeneutica colectiva. Colombia Utopía Siglo 21:43-54

Gibbons $M$ et al (1994) The new production of knowledge: the dynamics of science and research in Contemporary societies. SAGE Publications Ltd

Herrador-Valencia D, Mendizábal-Riera E, Boada-i-Juncà M (2012) Participatory action research applied to the management of natural areas: the case study of Cinquera in El Salvador. J Latin Am Geogr 11(1):45-65. https://doi.org/10.1353/lag.2012.0009
Hill R et al (2019) Working with indigenous, local and scientific knowledge in assessments of nature and nature's linkages with people. Curr Opin Environ Sustain 43:8-20. https://doi.org/10.1016/j. cosust.2019.12.006

Johannesen RL (1971) The emerging concept of communication as dialogue. Q J Speech 57(4):373-382. https://doi.org/10.1080/ 00335637109383082

Johnson JT et al (2016) Weaving Indigenous and sustainability sciences to diversify our methods. Sustain Sci 11(1):1-11. https:// doi.org/10.1007/s11625-015-0349-x (Springer Japan)

Kovach M (2010) Conversational method in indigenous research. First Peoples Child Family Rev 5(1):40-48. https://doi.org/10. 7202/1069060ar

Leff E (2004) Racionalidad ambiental y diálogo de saberes. POLIS, Revista Latinoamericana, $\mathrm{p} 7$

Ley del Sistema de Planificación Integral del Estado - SPIE. Ley 777 de 21 de enero de 2016. Estado Plurinacional de Bolivia

Lieberman A (1986) Collaborative research: working with, not working on. Educ Leadersh 43(5):28-32

Lipari L (2009) Listening otherwise: the voice of ethics. Int J Listening 23(1):44-59. https://doi.org/10.1080/10904010802591888

Lipari L (2010) Listening, thinking, being. Commun Theory 20(3):348-362. https://doi.org/10.1111/j.1468-2885.2010. 01366.x

Louis RP (2007) Can you hear us now? Voices from the margin: Using indigenous methodologies in geographic research. Geogr Res 45(2):130-139. https://doi.org/10.1111/j.1745-5871.2007. 00443.x

Miraftab F (2009) Insurgent planning: situating radical planning in the global south. Planning Theory 8(1):32-50. https://doi.org/10. $1177 / 1473095208099297$

Mistry J, Berardi A (2016) Bridging indigenous and scientific knowledge. Science 352(6291):1274-1275. https://doi.org/10.1126/ science.aaf 1160

Montana J (2017) Accommodating consensus and diversity in environmental knowledge production: achieving closure through typologies in IPBES. Environ Sci Policy 68:20-27. https://doi.org/10. 1016/j.envsci.2016.11.011 (Elsevier Ltd)

Muller S (2012) "Two ways": bringing indigenous and non-indigenous knowledges together. In: Weir JK (ed) Country native title and ecology. ANU E Press, pp 59-79

Nicholls R (2009) Research and Indigenous participation: critical reflexive methods. Int J Soc Res Methodol 12(2):117-126. https:// doi.org/10.1080/13645570902727698

Pacheco D (2016) Vision de Bolivia ante los desafios del Cambio Climatico y Medio Ambiente. La Paz

Phillips LJ (2011) Analysing the dialogic turn in the communication of research-based knowledge: an exploration of the tensions in collaborative research. Public Underst Sci 20(1):80-100. https:// doi.org/10.1177/0963662509340092

Phillips L, Napan K (2016) What's in the "co"? Tending the tensions in co-creative inquiry in social work education. Int J Qual Stud Educ 29(6):827-844. https://doi.org/10.1080/09518398.2016.1162869

Phillips L et al (2018) De-romanticising dialogue in collaborative health care research: a critical, reflexive approach to tensions in an action research project's initial phase. Qualitative Res Med Healthcare 2(1):1-13. https://doi.org/10.4081/qrmh.2018.7178

Quiroz V (2006) Pensamiento andino y critica postcolonial. Universidad Nacional Mayor de San Marcos, Un estudio de Rosa Cuchillo de Oscar Colchado

Reid RS et al (2016) Evolution of models to support community and policy action with science: balancing pastoral livelihoods and wildlife conservation in savannas of East Africa. Proc Natl Acad Sci USA 113(17):4579-4584. https://doi.org/10.1073/pnas.09003 13106 
Rist S et al (2011) Endogenous knowledge: implications for sustainable development. In: Wiesmann U, Hurni H (eds) Research for sustainable development: foundations, experiences, and perspectives Perspectives of the Swiss National Centre of Competence in Research (NCCR) NorthSouth. University of Bern, Bern, pp $119-146$

Rivera S (1997) La noción de "derecho" o las paradojas de la modernidad postcolonial: indígenas y mujeres en Bolivia. Temas sociales Revista de Sociologia UMSA 19:27-52. https://doi.org/10.1007/ s10551-013-1620-7

Rivera S (2012) Ch'ixinakax utxiwa: A reflection on the practices and discourses of decolonization. South Atlantic Q 111(1):95-109. https://doi.org/10.1215/00382876-1472612

Rivera S (2015) Violencia e interculturalidad Paradojas de la etnicidad en la Bolivia de hoy. Revista Telar del Instituto Interdisciplinario de Estudios Latinoamericanos 10(15):49-70

Rodríguez I, Inturias ML (2018) Conflict transformation in indigenous peoples' territories: doing environmental justice with a "decolonial turn." Dev Stud Res 5(1):90-105. https://doi.org/10.1080/ 21665095.2018.1486220

Rodríguez I et al (2016) 'A propósito del fuego: diálogo de saberes y justicia cognitiva en territorios indígenas culturalmente frágiles', trilogía. Ciencia Tecnología y Sociedad 8(15):97-118. https://doi. org/10.22430/21457778.399

Rousseau S, Hudon A (2017) Indigenous women transform the politics of representing women. In: Indigenous women's movements in Latin America, pp 55-81. https://doi.org/10.1057/ 978-1-349-95063-8

Shotter J (2009) Listening in a way that recognizes/realizes the world of "the other." Int J Listening 23(1):21-43. https://doi.org/10.1080/ 10904010802591904
Smith LT (2012) Decolonizing methodologies: research and indigenous people. Zed Books, New York

Spivak G (1990) Questions of multiculturalism. In: Harasym S (ed) Post-colonial critic. Interviews, strategies, dialogues. Routledge, New York, pp 59-60

Steelman T et al (2015) Practicing the science of sustainability: the challenges of transdisciplinarity in a developing world context. Sustain Sci 10(4):581-599. https://doi.org/10.1007/ s11625-015-0334-4

Tapia Ponce N (2016) El diálogo de saberes y la investigación participativa revalorizadora: Contribuciones y desafíos al desarrollo sustentable. In: Delgado F, Rist S (eds) Ciencias, diálogo de saberes y transdisciplinariedad. Aportes teórico metodológicos para la sustentabilidad alimentaria y del desarrollo. La Paz, Plural Editores, pp 89-118

Vásquez-Fernández AM et al (2018) Co-creating and decolonizing a methodology using indigenist approaches: alliance with the Asheninka and Yine-Yami peoples of the Peruvian Amazon. ACME 17(3):720-749

Watson V (2006) Deep difference: diversity, planning and ethics. Planning Theory 5(1):31-50. https://doi.org/10.1177/1473095206 061020

Watson V (2016) Shifting approaches to planning theory: global North and South. Urban Planning 1(4):32-41. https://doi.org/10.17645/ up.v1i4.727

Publisher's Note Springer Nature remains neutral with regard to jurisdictional claims in published maps and institutional affiliations. 